\title{
Mycosphaerella and Teratosphaeria leaf spot diseases of Eucalyptus globulus in Ecuador
}

\author{
Andreas Bernreiter ${ }^{1}$ - Rosalia Garcia Teijeiro ${ }^{1} \cdot$ Patricia Garrido $^{2} \cdot$ Luis Ramos $^{2}$
}

Received: 9 February 2016 / Accepted: 2 May 2016 / Published online: 12 May 2016

(C) Australasian Plant Pathology Society Inc. 2016

\begin{abstract}
Mycosphaerella and Teratosphaeria leaf spot diseases were detected for the first time in Ecuador. Fungi were isolated from leaf spots on Eucalyptus globulus plants growing in the Andean Highlands at altitudes higher than $2610 \mathrm{~m}$. Teratosphaeria molleriana and Mycosphaerella lateralis were identified based on morphological characteristics and sequence analysis. Most leaf spots were associated with diverse isolates from the Cladosporium cladosporoides complex.
\end{abstract}

Keywords Eucalyptus globulus · Leaf spot .

Mycosphaerella $\cdot$ Teratosphaeria $\cdot$ Ecuador

Eucalyptus trees are native to Australia, but due to their fast growth, they are now used worldwide for timber and pulp production. In Latin America, increasing numbers of plantations of Eucalyptus have appeared, thus the introduction of Eucalyptus fungal pathogens previously described in other continents has also increased. In South-America, there were reports about Mycosphaerella and Teratosphaeria leaf diseases (MLD, TLD) in Brazil (Teodoro et al. 2012) and in Uruguay (Pérez et al. 2009, 2013). These studies report severe defoliation to Eucalyptus plants and also indicate that introduction of plant pathogens may threaten native Myrtaceae. Considering these problems, the increasing severity of

Andreas Bernreiter

mapsylno@live.de

Prometeo Project Researcher (SENESCYT), Quito, Ecuador

2 Ecuadorian Agency for Quality Assurance in Agriculture, AGROCALIDAD, Av Interoceanica km 14.5,

170184 Tumbaco, Ecuador
MLD/TLD diseases on Eucalyptus plantations and the reported evidence of fungal host jumps, we investigated the presence of MLD/TLD on Eucalyptus globulus, the predominant Eucalyptus species in Ecuador.

Commercial plantations of E. globulus have rapidly expanded during the last two decades in the province of Pichincha, which is located in the Andes. Its Mediterraneantype climate is well suited for rapid growth of E. globulus. Although there have not been any previous records about the impact of MLD/TLD, a rapid increase of leaf spots has been reported the last years.

During the spring and summer of 2015, E. globulus plantations were surveyed for the presence of leaf spots and the impact of the disease on tree growth was estimated. An evaluation of the severity and the economical impact of the disease were beyond the scope of this study. Diminished tree growth, due to a reduction in green leaf area, was reported in more severely affected plantations. Leaf spots were observed in all surveyed areas, though significant differences in the abundance of leaf spots were observed between plantations. In a few plantations, the affected leaf area covered up to $50 \%$ of the surface. Leaf spots were observed on both juvenile and adult leaves, while lesions were more frequent on senescing leaves, which indicate the increased presence of saprophytic species or secondary invaders of diseased tissue. Most lesions were yellow to brown in colour, with irregular shape and the lesion borders had reddish margins.

In order to identify which primary pathogens cause symptoms of MLD/TLD, samples were collected during surveys of plantations in Quito and near to Quito, in the province of Pichincha. Leaf tissue samples were collected at an altitude between $2610 \mathrm{~m}$ and $2810 \mathrm{~m}$ between March and June 2015. Isolations from lesions with perithecia followed the procedure 


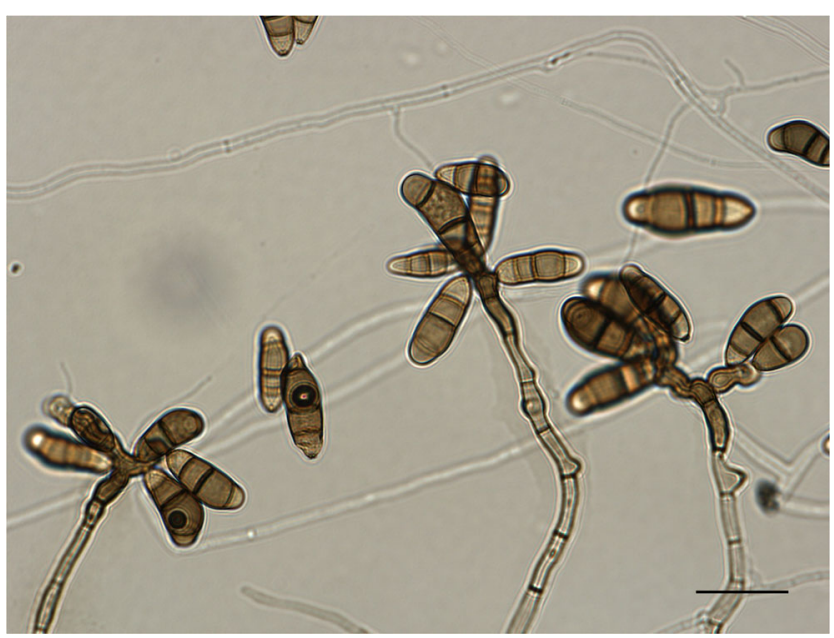

Fig. 1 Mycosphaerella lateralis (KU198344). Macroconidia. Scale bar $=10 \mu \mathrm{m}$

described by Crous (1998). Ascospores released from perithecia were collected on malt extract agar (MEA). Petri dishes were then incubated in the dark at approximately $25{ }^{\circ} \mathrm{C}$ during the daytime and $15{ }^{\circ} \mathrm{C}$ during the nighttime. After $48 \mathrm{~h}$, plates were examined for the presence of ascospores that had been ejected onto the surface of the medium. Germinating ascospores were then transferred to fresh MEA plates to generate monosporic cultures.

Several Mycosphaerella lateralis isolates derived from yellow spots of juvenile leaves of approximately $2 \mathrm{~mm}$ diameter were observed. The colonies appeared as grayish aerial mycelia with irregular shape on MEA. Teratosphaeria molleriana isolates appeared from small dark brown spots on juvenile leaves. The colonies were dark brown with irregular shapes on MEA. To observe conidia and conidial structures, slide culture technique (Riddle 1950) was used and cultures were grown for 2 weeks in a PDA medium before microscopic examination (Fig. 1).
Conidia and conidial growth was observed as described for Pseudocercospora and Teratosphaeria species (Crous et al. 2007). Both T. molleriana and M. lateralis are known to infect E. globulus leaves (Jackson et al. 2004; Maxwell et al. 2003). Diverse isolates from the Cladosporium cladosporoides (Genbank Accession: KU198345, KU198346, KU198347, KU198348) complex were simultaneously isolated with the mentioned MLD/TLD strains. Isolates of the fungal cultures were deposited in the culture collection of the Phytopathology Unit at Agrocalidad, Ecuador (Table 1).

For molecular characterization of the fungal isolates, DNA was extracted using a standard cetyltrimethyl ammonium bromide (CTAB) procedure, as described previously (Doyle and Doyle 1987). Polymerase chain reaction (PCR) analysis was performed by sequencing of the ITS region according to the method of White et al. (1990) with primers ITS1 (5'-TCC GTA GGT GAA CCT GCG-3') and ITS4 (5'-TCC TCC GCT TAT TGA TAT- $\left.3^{\prime}\right)$. The PCR product was separated by electrophoresis on $1 \%$ agarose gel in a $1 \times$ TBE (Tris-BorateEDTA) buffer, stained with SYBR Safe (Invitrogen) and visualized with a transilluminator. Subsequently, the PCR products were sequenced in both directions with the same primers used for the PCR amplifications by a commercial company (Macrogen Inc., Korea). All sequences obtained in this study were deposited in GenBank and accession numbers are shown in Table 1.

Identification of M. lateralis and T. molleriana was done by BLASTn analysis of the 370-bp sequence (KU198343) and 571 bp sequence (KU198344), which resulted in $>99 \%$ homology with the T. molleriana strain CBS 122905 (KF901626) from Chile and several other T. molleriana spp. and in $100 \%$ with the M. lateralis strain CPC:13,264 (GQ852741) from Australia and other M. lateralis spp., respectively. This is the first time that Teratosphaeria molleriana and Mycosphaerella lateralis have been found in Ecuador.

Table 1 Fungal isolates and fungal references used in that study

\begin{tabular}{lllll}
\hline Fungus & Culture no. & Host & Location & $\begin{array}{l}\text { Genbank accession } \\
\text { no. (ITS) }\end{array}$ \\
\hline Teratosphaeria molleriana & ANB15MIC02 & Eucalyptus globulus & Pichincha, Ecuador & KU198344 \\
Mycosphaerella lateralis & ANB15QP002 & E. globulus & Pichincha, Ecuador & KU198343 \\
Cladosporium cladosporoides & ANB15RYB02 & E. globulus & Pichincha, Ecuador & KU198345 \\
C. cladosporoides & ANB15RYB50 & E. globulus & Pichincha, Ecuador & KU198346 \\
C. cladosporoides & ANB15RYB30 & E. globulus & Pichincha, Ecuador & KU198347 \\
C. cladosporoides & ANB15RYB04 & E. globulus & Pichincha, Ecuador & KU198348 \\
T. molleriana & CBS122905 & E. globulus & Chile & KF901626 \\
M. lateralis & CPC:13264 & E. globulus & Australia & GQ852741 \\
\hline
\end{tabular}


Acknowledgments The authors are thankful to the Secretaría de Educación Superior, Ciencia, Tecnología e Innovación de la República del Ecuador (SENESCYT), its Prometeo Project and Agrocalidad, Ecuador for their financial support.

\section{References}

Crous PW (1998) Mycosphaerella spp. and their anamorphs associated with leaf spot diseases of eucalyptus. Mycol Mem 21:1-170

Crous PW, Braun U, Groenewald JZ (2007) Mycosphaerella is polyphyletic. Stud Mycol 58:1-32. doi:10.3114/sim.2007.58.01

Doyle JJ, Doyle JL (1987) A rapid DNA isolation procedure for small quantities of fresh leaf tissue. Phys Bull 19:11-15

Jackson SL, Maxwell A, Neumeister-Kemp HG, Dell B, Hardy GESJ (2004) Infection, hyperparasitism and conidiogenesis of Mycosphaerella lateralis on Eucalyptus globulus in Western Australia. Australas Plant Pathol 33(1):49-53

Maxwell A, Dell B, Neumeister-Kemp HG, St J, Hardy GE (2003) Mycosphaerella species associated with eucalyptus in South-
Western Australia: new species, new records and a key. Mycol Res 107(Pt 3):351-359

Pérez G, Hunter GC, Slippers B, Pérez C, Wingfield BD, Wingfield MJ (2009) Teratosphaeria (Mycosphaerella) nubilosa, the causal agent of Mycosphaerella leaf disease (MLD), recently introduced into Uruguay. Eur J Plant Pathol 125:109-118

Pérez CA, Wingfield MJ, Altier N, Blanchette RA (2013) Species of Mycosphaerellaceae and Teratosphaeriaceae on native Myrtaceae in Uruguay: evidence of fungal host jumps. Fungal Biol 117(2): 94-102. doi:10.1016/j.funbio.2012.12.002

Riddle RW (1950) Permanent stained mycological preparation obtained by slide culture. Mycologia 42:265-270

Teodoro MG, Ferreira MA, Guimarães LMS, Mafia RG, Groenewald JZ, Crous PW, Alfenas AC (2012) Mycosphaerella and Teratosphaeria species associated with leaf diseases on Eucalyptus globulus in southern Brazil. Phytopathol Mediterr 51(2):355-364

White TJ, Bruns T, Lee S, Taylor JW (1990) Amplification and direct sequencing of fungal ribosomal RNA genes for phylogenetics. In: Innis MA, Gelfand DH, Sninsky JJ, White T J (eds) PCR protocols: a guide to methods and applications. Academic Press, Inc., New York, pp. 315-322 